\title{
Radiopacity of Experimental Composite Resins Containing Radiopaque Materials
}

\author{
Yujin AOYAGI ${ }^{1}$, Hidekazu TAKAHASHI ${ }^{1}$, Naohiko IWASAKI ${ }^{1}$, Ei-ichi HONDA ${ }^{2}$ and Toru KURABAYASHI ${ }^{3}$ \\ ${ }^{1}$ Advanced Biomaterials, Department of Restorative Sciences, Division of Oral Health Sciences, Graduate School, Tokyo Medi- \\ cal and Dental University, Yushima 1-5-45, Bunkyo-ku, Tokyo 113-8549, Japan \\ ${ }^{2}$ Department of Oral and Maxillofacial Radiology, Graduate School of Dentistry, The University of Tokushima Kuramoto 3- \\ 18-15, Tokushima, Tokushima 770-8504, Japan \\ ${ }^{3}$ Oral and Maxillofacial Radiology, Department of Oral Restitution, Division of Oral Health Sciences, Graduate School, Tokyo \\ Medical and Dental University, Yushima 1-5-45, Bunkyo-ku, Tokyo 113-8549, Japan \\ Corresponding author, E-mail:aoyagi.abm@tmd.ac.jp
}

Received February 3, 2005/Accepted June 7, 2005

\begin{abstract}
This study aimed to investigate the relationship between the radiopacity of an experimental light-cured composite resin and the amount and type of its radiopaque material: $\mathrm{Ti}, \mathrm{SrCO}_{3}, \mathrm{ZrO}_{2}, \mathrm{BaSO}_{4}$, or $\mathrm{Bi}_{2} \mathrm{O}_{3}$. Radiopacity of each material was evaluated in terms of aluminum equivalent thickness using an aluminum step wedge. Then, the half-value layer thickness of the experimental composite resin, which had an aluminium equivalent thickness of $1 \mathrm{~mm}$, was evaluated. It was found that the effects of elemental composition were not identical when evaluated in terms of aluminum equivalent thickness and by halfvalue layer. Nevertheless, both measurement methods indicated that radiopacity increased with increase in radiopaque material content as well as increase in atomic number of the element.
\end{abstract}

Key words : Aluminum equivalent thickness, Half-value layer, Composite resin

\section{INTRODUCTION}

Of late, it has become increasingly difficult to differentiate composite resins from actual teeth because of the vast esthetic improvements of composite resins. Therefore, many dental composite resins have a radiopacity characteristic to be distinguished from teeth for diagnosis ${ }^{1-2)}$. Alternatively, fluorescence observation has been suggested as another method to distinguish composite resin ${ }^{3)}$. Several studies have evaluated the radiopacity of composite resins ${ }^{4-8)}$. However, these studies merely estimated the radiopacity of commercial products, and then compared these products with enamel and dentin ${ }^{1,2,4-8)}$. Few studies ${ }^{9,10)}$ have evaluated the elemental compositions of these products to explain radiopacity; and even so, these studies did not clearly discuss the correlation between the amount of radiopaque materials and the intensity of radiopacity.

Radiopacity of dental composite resins is usually evaluated according to ISO standard $4049: 2000^{11)}$, which measures aluminum equivalent thickness using a dental X-ray unit. The intensity of an X-ray beam is affected and altered by three components of an Xray unit: tube voltage, filter, and bulb structure. As a result, radiographic images vary according to the $\mathrm{X}$-ray sensor and X-ray unit used - even though the tube voltage is the same. This means that aluminum equivalent thickness constitutes only a relative value of each condition. Against this background, we believe that it is necessary to obtain absolute values that are based on fundamental radiological principles.

In radiology, a half-value layer is defined as "the thickness of an absorber, such as aluminum, required to reduce the number of $\mathrm{X}$-ray photons passing through it by one half" ${ }^{12}$, and it is usually used to determine the radiopacity of a material. The halfvalue layer is needed to calculate the effective energy of an X-ray unit, the equivalent value, and the linear absorption coefficient of a material. In radiological terms, dental X-ray units are evaluated by their differences in effective energy - which is calculated using linear absorption coefficient based on half-value layer. The intensity of an X-ray beam is determined by the linear absorption coefficient $(\mu)$ and thickness (x) of a material. The initial X-ray intensity $\left(\mathrm{I}_{0}\right)$ is calculated by the following formula ${ }^{13)}$ :

$$
I=I_{0} e^{-\mu x}
$$

When transmitted through the half-value layer of a material, the X-ray intensity is half of the initial X-ray intensity, as expressed below:

$$
I=0.5 I_{0}
$$

Therefore, the relationship between the half-value layer $(\mathrm{HVL}, \mathrm{cm})$ and the linear absorption coefficient $(\mu)$ of a material is given as:

$$
\mu(H V L)=\log _{e} 2
$$

Barium (Ba), strontium ( $\mathrm{Sr}$ ), zirconium $(\mathrm{Zr})$, and titanium (Ti) have been used lately as radiopaque materials for dental composite resins. $\mathrm{Ti}$ is used for metal copings or prosthetic frameworks, $\mathrm{Zr}$ for dental ceramic restorations, bismuth (Bi) is applied as a radiopaque sealer in endodontic treatments, and $\mathrm{Ba}$ is the most commonly used radiopaque material in medicine and dentistry. However, it is yet to be fully clarified which is the most 
effective radiopaque material for composite resins. Therefore, the present study aimed to examine the relationship between the radiopacity of an experimental light-cured composite resin and the amount and type of the radiopaque material that it contained namely titanium, strontium carbonate, zirconium oxide, barium sulfate, or bismuth oxide.

\section{MATERIALS AND METHODS}

Experimental radiopaque light-cured composite resins Table 1 lists the radiopaque materials and resin components used in the present study.

Titanium (Ti), strontium carbonate $\left(\mathrm{SrCO}_{3}\right)$, zirconium dioxide $\left(\mathrm{ZrO}_{2}\right)$, barium sulfate $\left(\mathrm{BaSO}_{4}\right)$, and di-bismuth trioxide $\left(\mathrm{Bi}_{2} \mathrm{O}_{3}\right)$, all used as powders without any purification or sieving, were selected as radiopaque materials for this study.

The matrix resin of all experimental composites was $70 / 30$ mass $\%$ of urethane dimethacrylate (UDMA) and triethyleneglycol dimethacrylate (TEGDMA), while 0.50 mass \% of camphorquinone (CQ) and 1.00 mass $\%$ of dimethylaminoethylmethacrylate (DMAEMA) were added as the photoinitiator and reducing agent, respectively.

Experimental radiopaque light-cured composite resins were prepared as follows. Spherical-shaped silica powder and the powder of one of the radiopaque materials were mixed as filler for the composite resin at radiopaque material contents of $0,20,40,60,80$, and 100 vol\%. Radiopaque material contents of 50 and 10 vol\% were also mixed for $\mathrm{SrCO}_{3}$ and $\mathrm{Bi}_{2} \mathrm{O}_{3}$, respectively. Filler silanization was not performed. The filler was then mixed with the matrix resin at a filler content of $12.5 \mathrm{vol} \%$. In this manner, 27 kinds of experimental radiopaque light-cured composite resin were prepared.

\section{Specimens preparation}

For aluminum equivalent thickness measurement, bar-shaped specimens $(2.0 \times 2.0 \times 25.0 \mathrm{~mm})$ were prepared. For half-value layer measurement, sheetshaped specimens $(35.0 \times 35.0 \times 0.5 \mathrm{~mm}$ and $35.0 \times 35.0$ $\times 0.1 \mathrm{~mm})$ were prepared.

Each bar-shaped specimen was fabricated using a polypropylene mold as follows. One experimental radiopaque light-cured composite resin was packed into the mold, covered with plastic strips and a glass slide, and irradiated for five minutes from both sides in a laboratory light-polymerizing unit (Labolight II, GC, Tokyo, Japan). Then, the bar-shaped specimen was polished to a thickness of $1.00 \mathrm{~mm}$ using a precise polishing machine (Dialap, Malto, Tokyo, Japan) with SiC paper (\#600) under dry conditions. Three specimens were prepared for each composite resin at radiopaque material contents of $0,20,40,60,80$, and 100 vol\%.

Sheet-shaped specimens were fabricated using two $50 \times 50 \times 2 \mathrm{~mm}$ polypropylene plates. Brass strip of $0.5 \mathrm{~mm}$ thickness or plastic strip of $0.1 \mathrm{~mm}$ thickness was placed on the polypropylene plate to create a $35 \times 35 \mathrm{~mm}$ space. The experimental radiopaque light-cured composite resin was filled into this space, covered with the other polypropylene plate, and irradiated in the laboratory light-polymerizing unit for five minutes from both sides. Five sheets of each thickness were prepared with an experimental radiopaque light-cured composite resin at radiopaque material contents of $60 \mathrm{vol} \% \mathrm{Ti}, 50$ vol\% $\mathrm{SrCO}_{3}, 40$ vol\% $\mathrm{ZrO}_{2}, 40$ vol\% $\mathrm{BaSO}_{4}$, and 10 vol $\% \mathrm{Bi}_{2} \mathrm{O}_{3}$. The aluminum equivalent thickness of these experimental radiopaque light-cured composite resins was approximately $1.0 \mathrm{~mm}$.

The thickness of each specimen was measured using a micrometer (CPM15-25DM, Mitsutomo, Tokyo, Japan; minimum reading is $0.001 \mathrm{~mm}$ ).

\section{Aluminum equivalent thickness measurement}

An aluminum step wedge (99.5\% purity; step depth: $0.5 \mathrm{~mm}$; thickness: $0.5 \mathrm{~mm}$ to $7.0 \mathrm{~mm}$; width: 3.0 $\mathrm{mm}$ ) was prepared as the reference material. A barshaped specimen and the aluminum step wedge were simultaneously irradiated by a dental X-ray unit (CCX AD 33, Trophy, France; tube voltage: $70 \mathrm{kV}_{\mathrm{p}}$; tube current: $8 \mathrm{~mA}$; exposure time: 0.5 seconds; focus-subject distance (FSD): $38 \mathrm{~cm})$. The X-ray

Table 1 Materials used in the present study

\begin{tabular}{ccc}
\hline Material & Product Name & Company \\
\hline Barium sulfate & Barium sulfate (Grade 1) & Wako Pure Chemical Industries \\
Titanium powder & TMP-350 (purity: 99\%) & Sumitomo Sitix Co. \\
Strontium carbonate & Strontium carbonate (purity: 95.0\%) & Wako Pure Chemical Industries \\
Zirconium (IV) oxide & FZCA-4C (purity: 95.28\%) & Tateho Chemical Industries Co. \\
Bismuth (III) oxide & Bismuth (III) oxide (Grade 1) & Wako Pure Chemical Industries \\
Spherical-shaped silica filler & PLV-6 & Tatsumori Ltd. \\
UDMA & Art resin SH-500B & Negami Chemical \\
TEGDMA & 3G & Shin Nakamura \\
Camphorquinone & Camphorquinone & Aldrich Chemical \\
Dimethylaminoethylmethacrylate & (2-dimethylamino) ethylmethacrylate & Wako Pure Chemical Industries \\
\hline
\end{tabular}


image was immediately recorded using an image sensor of an X-ray image capturing unit (Compuray, Yoshida, Tokyo, Japan) in tagged image file (TIFF) format. Images were analyzed using an image analyzing software (NIH Image ver. 1.62, National Institutes of Health, USA) on a personal computer (Power Mac G4, Apple, USA). Minimum and maximum gray levels were linearly scored in a range between 0 (white; X-ray was completely absorbed) and 255 (black; X-ray was completely passed). An area size $-20 \times 20$ pixels - was selected on each step of the aluminum step wedge and its mean gray level calculated. The same procedure was repeated for each specimen at three randomly selected areas. After which, a scatter diagram was plotted using the results of the thickness of the aluminum step wedge and its gray level. The aluminum equivalent thickness of each specimen was then calculated based on gray level using regression analysis of the aluminum step wedge. Effective atomic number $\left(Z_{\tau}\right)$ was calculated using the atomic numbers $\left(\mathrm{Z}_{1}, \mathrm{Z}_{2}, \cdots, \mathrm{Z}_{n}\right)$ of each element in the material and electron ratios $\left(a_{1}\right.$, $a_{2}, \cdots \cdots, a_{n}$ ) of the elements in the material by the following formula ${ }^{13)}$ :

$$
Z_{\tau}=\left(a_{1} Z_{1}^{2.94}+a_{2} Z_{2}^{2.94}+\cdots \cdots+a_{n} Z_{n}^{2.94}\right)^{1 / 2.94}
$$

\section{Half-value layer measurement}

Half-value layer measurements were done using two types of dental X-ray unit (CCX AD 33, irradiation condition identical to that given above, and HI-EMIX D-RV-90, Tokyo Emix, Japan; tube voltage: $60 \mathrm{kV}_{\mathrm{cp}}$; tube current: $8 \mathrm{~mA}$; exposure time: 0.5 seconds). The experimental schema is illustrated in Fig. 1.

Two lead plates were prepared. One was a $90 \times$ $80 \times 1.5 \mathrm{~mm}$ plate with a $1.5-\mathrm{cm}$ diameter hole for an aperture, and the other was a $40 \times 40 \times 10 \mathrm{~mm}$ plate with a $2.0-\mathrm{cm}$ diameter for a sample stage. An ioni-

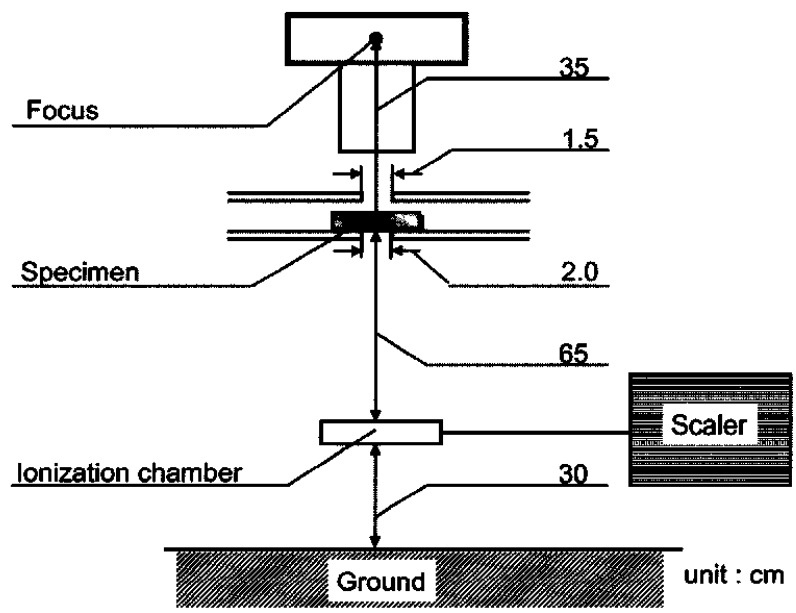

Fig. 1 Schematic illustration of half-valve layer (HVL). zation chamber (660-4A, Victoreen, Moedling, Austria) with a scale meter (Victoreen 660, Victoreen, Moedling, Austria) was set at $30 \mathrm{~cm}$ above the ground. The sample stage was located at a distance of $65 \mathrm{~cm}$ from the ionization chamber. A specimen of selected thickness was then placed on the sample stage and covered by the other lead plate with the aperture. Distance between the specimen and the focus of the X-ray source was $35 \mathrm{~cm}$.

Radiation exposure with and without the specimen was measured by the ionization chamber. When irradiation dose was half of that without specimen, the thickness of the radiopaque material was measured and recorded as the half-value layer of the composite resin. If the half-value layer was not determined using the prepared sheet, it was calculated using interpolation method. An aluminum half-value layer attenuator set (Al 99.9\% purity; RMI 115A \& RMI 115H, Gammex RMI, WI, USA) was used to determine the half-value layer of aluminum. Linear absorption coefficients of the experimental composite resins were thereby calculated.

In addition, half-value layers were subjected to statistical analysis using two-way ANOVA and Tukey's test $(\alpha=0.05)$.

\section{RESULTS}

\section{Aluminum equivalent thickness measurement}

Fig. 2 shows the relationship between the thickness of the aluminum step wedge and the gray level. As shown, gray level of the aluminum step wedge increased proportionally with increasing aluminum thickness in the density profile.

Fig. 3 shows the relationship between the radiopaque material content of filler and aluminum equivalent thickness. As shown, the aluminum equivalent thickness of radiopaque materials in-

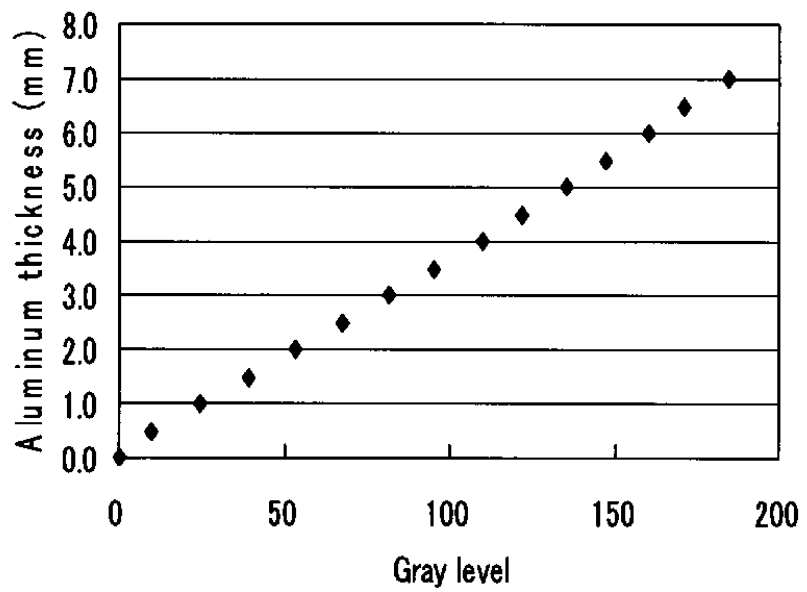

Fig. 2 Relationship between gray level and aluminum step wedge. 


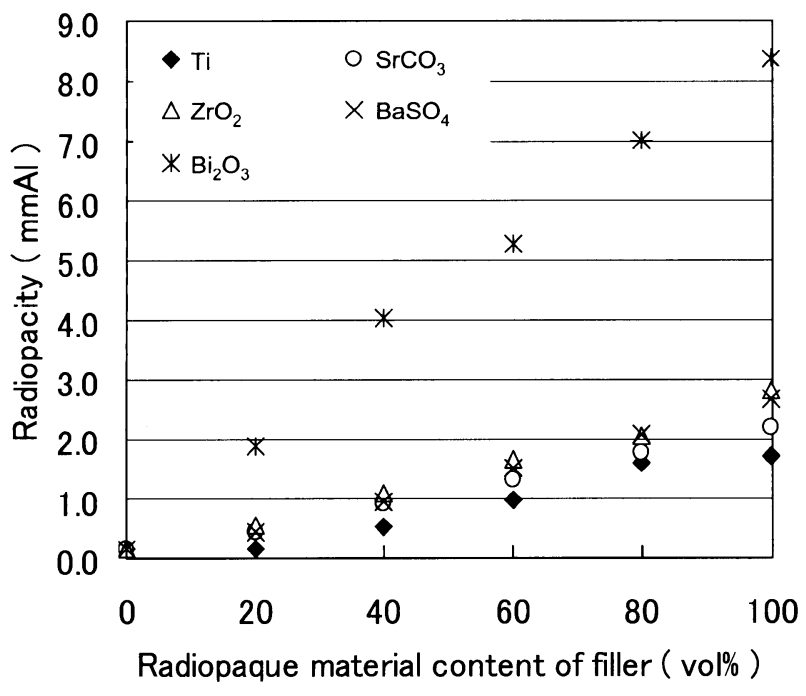

Fig. 3 Relationship between radiopaque material content and aluminum equivalent thickness.

creased as the radiopaque material content increased. Especially for $\mathrm{Ti}$, the relation between radiopaque material content and aluminum equivalent thickness showed a sigmoid curve.

Radiopacity increased with increase in radiopaque material content. Table 2 shows the amount of radiopaque material calculated for aluminum equivalent thickness of $1.0 \mathrm{~mm}$. When ranked in terms of the volumetric amount of radiopaque material calcu- lated for $1.0-\mathrm{mm}$ aluminum equivalent thickness, the materials were ranked as follows: $\mathrm{Bi}_{2} \mathrm{O}_{3}<\mathrm{BaSO}_{4}=\mathrm{ZrO}_{2}$ $<\mathrm{SrCO}_{3}<\mathrm{Ti}$. When ranked in terms of effective atomic number, the same trend was observed. When ranked in terms of the mass amount of radiopaque material calculated for $1.0-\mathrm{mm}$ aluminum equivalent thickness, the materials were ranked as follows: $\mathrm{Bi}_{2} \mathrm{O}_{3}<\mathrm{BaSO}_{4}<\mathrm{SrCO}_{3}<\mathrm{ZrO}_{2}<\mathrm{Ti}$. When ranked in terms of elemental mass \%, the same trend was observed. When ranked in terms of linear absorption coefficient, the materials were ranked as follows: $\mathrm{Ti}<\mathrm{BaSO}_{4}<\mathrm{Bi}_{2} \mathrm{O}_{3}<\mathrm{SrCO}_{3}<\mathrm{ZrO}_{2}$.

\section{Half-value layer measurement}

As shown in Table 3, half-value layers ranged from 1.32 to $2.89 \mathrm{~mm}$. Two-way ANOVA revealed that Xray unit and radiopaque material were significant. The half-value layer of CCX AD 33 was significantly higher than that of HI-EMIX D-RV-90. The halfvalue layers of $\mathrm{Ti}$ and $\mathrm{BaSO}_{4}$ were significantly higher than that of the other radiopaque materials. On the other hand, the half-value layer of $\mathrm{ZrO}_{2}$ was significantly smaller than that of the other radiopaque materials.

\section{DISCUSSION}

$\mathrm{Ti}, \mathrm{Sr}, \mathrm{Zr}, \mathrm{Ba}$, and $\mathrm{Bi}$ were selected as the radiopaque materials in the present study because they were already applied in clinically available dental materials

Table 2 The amount of the radiopaque material calculated for composite resin having 1.0-mm aluminum equivalent thickness

\begin{tabular}{lcccccc}
\hline & $\mathrm{Ti}$ & $\mathrm{SrCO}_{3}$ & $\mathrm{ZrO}_{2}$ & $\mathrm{BaSO}_{4}$ & $\mathrm{Bi}_{2} \mathrm{O}_{3}$ & $\mathrm{Al}^{*}$ \\
\hline Compound vol\% of filler & 60 & 50 & 40 & 40 & 10 & \\
Compound mass\% in composite resin & 22.9 & 17.0 & 19.1 & 15.4 & 8.3 & \\
Element mass\% in composite resin & 22.9 & 10.1 & 14.1 & 9.1 & 7.5 & \\
$\quad$ Density of composite resin (d) & 1.39 & 1.32 & 1.39 & 1.33 & 1.32 & $2.70^{* *}$ \\
Effective atomic number of composite & 13.4 & 16.8 & 19.8 & 23.1 & 31.4 & 13 \\
$\quad \mathrm{Z}^{3} \times \mathrm{d}$ & 3344 & 6259 & 10790 & 16394 & 40866 & 5932 \\
\hline reference & & & & & & \\
$* *$ density of metal & & & & & &
\end{tabular}

Table 3 Half-value layer (HVL) of the radiopaque composite resins and the aluminum equivalent value of HVL $\left(\mathrm{HVL} / \mathrm{HVL}_{\mathrm{Al}}\right)$

\begin{tabular}{|c|c|c|c|c|c|c|}
\hline & Ti 60vol\% & $\mathrm{SrCO}_{3} 50 \mathrm{vol} \%$ & $\mathrm{ZrO}_{2} 40 \mathrm{vol} \%$ & $\mathrm{BaSO}_{4} 40 \mathrm{vol} \%$ & $\mathrm{Bi}_{2} \mathrm{O}_{3} \quad 10 \mathrm{vol} \%$ & $\mathrm{Al}^{*}$ \\
\hline \multicolumn{7}{|l|}{ CCX AD 33} \\
\hline HVL & 2.89 & 1.91 & 1.36 & 2.80 & 2.02 & 2.10 \\
\hline $\mathrm{HVL} / \mathrm{HVL}_{\mathrm{Al}}$ & 1.38 & 0.91 & 0.65 & 1.33 & 0.96 & \\
\hline$\mu$ & 2.40 & 3.63 & 5.10 & 2.48 & 3.43 & 3.30 \\
\hline \multicolumn{7}{|l|}{ HI-EMIX D-RV-90 } \\
\hline HVL & 2.64 & 1.71 & 1.32 & 2.49 & 1.77 & 1.90 \\
\hline $\mathrm{HVL} / \mathrm{HVL}_{\mathrm{Al}}$ & 1.39 & 0.90 & 0.69 & 1.31 & 0.93 & \\
\hline$\mu$ & 2.63 & 4.05 & 5.25 & 2.78 & 3.92 & 3.65 \\
\hline
\end{tabular}

*reference 
to provide radiopacity. Ti, $\mathrm{SrCO}_{3}, \mathrm{ZrO}_{2}, \mathrm{BaSO}_{4}$, and $\mathrm{Bi}_{2} \mathrm{O}_{3}$ were chosen because these compounds are chemically stable, non-toxic, and composed of other elements that have a small radiopaque effect.

Silanization is well known to improve the interfacial properties of fillers and to increase the maximum amount of filler content. While there have been several reports on silanization of silica particles ${ }^{14,15)}$, silanization of the compounds used in the present study has not been fully investigated. Moreover, the effect of silanization on radiopacity has not been clearly explained. On these grounds, the radiopaque materials used in the present study were not silanized. As a result, filler content with the experimental radiopaque light-curing composite resin was controlled at a relatively small amount of $12.5 \mathrm{vol} \%$ - because if filler content were to exceed 12.5 vol\% of $\mathrm{BaSO}_{4}$, the consistency would not be uniform.

In the present study, volumetric filler content of radiopaque material was used versus the mass $\%$ generally used for the filler content of dental composite resins $^{16-18)}$. The radiopacity of a material is evaluated by the change in intensity of the radiation transmitted, which is affected by three materialrelated factors: density, thickness, and the atomic number of the elements which constitute the material. On these grounds, it is very important to evaluate the radiopacity of a material in terms of elemental density in unit volume.

Two X-ray units of different tube voltages were used. In the USA and European countries, X-ray units with $70 \mathrm{kV}$ tube voltage are popular, while in Japan X-ray units with $60 \mathrm{kV}$ tube voltage are popular ${ }^{10)}$. The linear absorption coefficients of aluminum obtained by CCX AD 33 and HI-EMIX D-RV-90 were calculated to be 3.30 and $3.65 \mathrm{~cm}^{-1}$, respectively. The density $(\rho)$ of aluminum is $2.698 \mathrm{~g} / \mathrm{cm}^{3}$ at $25^{\circ} \mathrm{C}$. According to the diagram of effective energy and mass attenuation coefficient $(\mu / \rho)^{19)}$, the mass attenuation coefficient of aluminum is $3.441 \mathrm{~cm}^{2} / \mathrm{g}$ at $20 \mathrm{keV}$ and $1.128 \mathrm{~cm}^{2} / \mathrm{g}$ at $30 \mathrm{keV}$. Therefore, the effective energy of CCX AD 33 and HI-EMIX D-RV-90 were computed as $29.64 \mathrm{keV}$ and $29.04 \mathrm{keV}$, respectively. Thus, the difference in effective energy between the two dental X-ray units was actually small in spite of different tube voltages. This could be explained by the different rectifying system of the two X-ray units: CCX AD 33 used a full-wave rectifier, while HI-EMIX D-RV-90 used an inverter. Therefore, HI-EMIX D-RV-90 showed a relatively high effective energy in spite of lower tube voltage.

The most popular X-ray detector in dentistry is the intraoral film, which is usually sensitive to X-ray beams at $40 \mathrm{keV}^{20)}$. However, the sensitivity of the ionization chamber is almost independent of the energy used in clinical diagnoses. The sensitivity of the CCD sensor used was not clearly elucidated; however, its sensitivity to X-ray energy might be similar to that of intraoral film. The gray scale of the CCD image was modified to increase in proportion with increase in aluminum thickness, according to the result of Fig.3. The effective energy of dental $\mathrm{X}$-ray units used in the present study was approximately $30 \mathrm{keV}$. The radiopacity results of aluminum equivalent thickness using the CCD sensor and those of half-value layer using the ionization chamber did not agree because the sensitivities of the X-ray detectors, CCD sensor, and ionization chamber were different. Radiopacity results might also change if intraoral film had been used for evaluation.

The density profile of aluminum showed a straight line. However, the aluminum equivalent thickness of experimental composites did not proportionally increase with increase in radiopaque material content. The edge effect of aluminum at $1.6 \mathrm{keV}$ is not observed in the X-ray energy range used in clinical diagnoses. However, $\mathrm{Ti}, \mathrm{Sr}, \mathrm{Zr}$, and $\mathrm{Ba}$ show the $\mathrm{K}$-edge effect at 5.0,16.1, 18.0, and $37.4 \mathrm{keV}$, respectively ${ }^{19)}$. Further, the characteristics of CCD sensor were not disclosed. For these reasons, aluminum equivalent thickness did not increase proportionally with the amount of radiopaque material. In other words, the aluminum equivalent thickness of the experimental composite resins in Table 2 would not be $2 \mathrm{~mm}$ if the thickness of the experimental composite resins were $2 \mathrm{~mm}$.

The aluminum equivalent thicknesses of 1-mm thick dentin and enamel were reported as 0.79 and $2.22 \mathrm{~mm}$, respectively ${ }^{1)}$. Those of the $1-\mathrm{mm}$ thick commercial composite resins reported in earlier papers were $1.65-2.52^{1)}, 1.40-3.00^{8)}$, and $0.73-3.72 \mathrm{~mm}^{10)}$. The aluminum equivalent thicknesses of the experimental composite resins containing radiopaque materials, except those with higher $\mathrm{Bi}_{2} \mathrm{O}_{3}$ content, were within the range of previous reports. As shown in Fig. $3, \mathrm{Ti}, \mathrm{SrCO}_{3}, \mathrm{ZrO}_{2}, \mathrm{BaSO}_{4}$, and $\mathrm{Bi}_{2} \mathrm{O}_{3}$ should constitute about $50,30,30,30$, and $8 \mathrm{vol} \%$, respectively for the aluminum equivalent thickness of dentin, and $60,40,40,40$, and $10 \mathrm{vol} \%$, respectively for the aluminum equivalent thickness of $1 \mathrm{~mm}$.

Atomic numbers - which affect radiopacity - of $\mathrm{Ti}, \mathrm{Sr}, \mathrm{Zr}, \mathrm{Ba}$, and $\mathrm{Bi}$ are $22,38,40,56$, and 83 , respectively. The measured aluminum equivalent thickness increased as element's atomic number increased. However, when comparing the half-value layers of $\mathrm{ZrO}_{2}$ and $\mathrm{BaSO}_{4}, \mathrm{ZrO}_{2}$ showed greater radiopacity despite the same volumetric content, similar density, and smaller effective atomic number and density. This result agreed with a previous paper which measured the aluminum equivalent thickness of commercial products ${ }^{10)}$. However, other elements contained in these commercial products might influence the reported result.

The effects of elemental composition on radiopacity evaluated in terms of aluminum equiva- 
lent thickness and by half-value layer were not identical. Nevertheless, the common underlying trend was that radiopacity increased with a greater amount of radiopaque material content and with a greater atomic number of the constituent element. Photoelectric absorption is related to $\mathrm{Z}^{3} \times \mathrm{d}^{13)}$. Therefore, radiopacity of a material should be inversely proportional to $\mathrm{Z}^{3} \times \mathrm{d}$. However, both aluminum equivalent thickness and half-value layer did not obey this theory. This was most probably due to the $\mathrm{K}$ edge effect and the different sensitivities of detectors.

In the present study, bismuth was the most radiopaque material. However, it is not used for composite resin fillers probably because of its poor mechanical properties in glass. Barium glass is known to hydrate easily ${ }^{21)}$, and the contents of $\mathrm{Ti}$ and $\mathrm{Zr}$ in glass are limited because of their high melting points. Therefore, the content of these radiopaque materials for glass filler of composite resins is somewhat limited.

Aluminum equivalent thickness measured using intraoral films might provide sufficient information for diagnoses in dental clinics. However, it should be borne in mind that aluminum equivalent thickness is easily influenced by the type of intraoral film used and by the irradiation conditions of the dental X-ray unit.

\section{CONCLUSIONS}

Considering the limitations of this study, the following conclusions were drawn:

1) Aluminum equivalent thickness of the experimental composite resins increased as the amount of radiopaque material content increased.

2) Aluminum equivalent thickness of the experimental composite resins depended on the atomic number of the constituent element.

3) Half-value layer of the five experimental composite resins varied according to the radiopaque material used.

\section{REFERENCES}

1) Stanford CM, Fan PL, Schoenfeld CM, Knoeppel R, Stanford JW. Radiopacity of light-cured posterior composite resins. J Am Dent Assoc 1987; 115: 722-724.

2) Akerboom HB, Kreulen CM, van Amerongen WE, Mol A. Radiopacity of posterior composite resins, composite resin luting cements, and glass ionomer lining cements. J Prosthet Dent 1993; 70: 351-355.

3) Tani K, Watari F, Uo M, Morita M. Discrimination between composite resin and teeth using fluorescence properties. Dent Mater J 2003; 22: 569-580.

4) Gurdal P, Akdeniz BG. Comparison of two methods for radiometric evaluation of resin-based restorative materials. Dentomaxillofac Radiol 1998; 27: 236-239.

5) Murchison DF, Charlton DG, Moore WS. Comparative radiopacity of flowable resin composites. Quintessence Int 1999; 30: 179-184.

6) Bouschlicher MR, Cobb DS, Boyer DB. Radiopacity of compomers, flowable and conventional resin composites for posterior restorations. Oper Dent 1999; 24: 20-25.

7) Hara AT, Serra MC, Haiter-Neto F, Rodrigues AL Jr. Radiopacity of esthetic restorative materials compared with human tooth structure. Am J Dent 2001; 14: 383386.

8) Attar N, Tam LE, McComb D. Flow, strength, stiffness and radiopacity of flowable resin composites. J Can Dent Assoc 2003; 69: 516-521.

9) Taira M, Toyooka H, Miyawaki H, Yamaki M. Studies on radiopaque composites containing $\mathrm{ZrO}_{2}-\mathrm{SiO}_{2}$ fillers prepared by the sol-gel process. Dent Mater 1993; 9: 167-171.

10) Toyooka H, Taira M, Wakasa K, Yamaki M, Fujita M, Wada T. Radiopacity of 12 visible-light-cured dental composite resins. J Oral Rehabil 1993; 20: 615-622.

11) ISO 4049:2000 Dental resin-based restorative materials. 3rd ed, International Organization for Standardization, Geneva, 2000.

12) Goaz PW, White SC. Oral radiology, 2nd ed, Mosby, St. Louis, 1987, pp.33.

13) Johns EH. The physics of radiology, 2nd ed, Charles $C$ Thomas Publisher, Illinois, 1961, pp.139-209.

14) Arksornnukit $M$, Takahashi H, Nishiyama N. Effects of silane coupling agent amount on mechanical properties and hydrolytic durability of composite resin after hot water storage. Dent Mater J 2004; 23: 31-36.

15) Arksornnukit $M$, Takahashi $H$, Nishiyama $N$, Pavasant P. Effect of heat and $\mathrm{pH}$ in silanation process on flexural properties and hydrolytic durabilities of composite resin after hot water storage. Dent Mater $\mathbf{J}$ 2004; 23: 175-179.

16) Ersoy M, Civelek A, L'hotelier E, Say CE, Soyman M. Physical properties of different composites. Dent Mater J 2004; 23: 278-283.

17) Soma H, Miyagawa $Y$, Ogura H. Setting and flexural properties of metal-resin composite using $\mathrm{Ag}-\mathrm{Cu}$ particles as filler and chemical accelerator. Dent Mater $J$ 2003; 22: 543-555.

18) Urapepon S, Kakuta K, Ogura H. Development of metal-resin composite restorative material. Part 5: Evaluation of the bonding between $\mathrm{Ag}-\mathrm{Sn}$ particle and 4-META coupling agent of the metal-resin composite. Dent Mater J 2003; 22: 137-145.

19) Hubbell HJ, Seltzer MS. Tables of X-ray mass attenuation coefficients and mass energy-absorption coefficients. Physical Reference Data [cited: 2005. Jan.28]. Available from URL: http://physics.nist.gov/ PhysRefData/XrayMassCoef/cover.html.

20) Dendy PP, Heaton B. Physics for diagnostic radiology, 2nd ed, Institute of Physics and Engineering, Philadelphia, 1999, pp.152-155.

21) Soderholm KJ, Zigan M, Ragan M, Fischlschweiger W, Bergman M. Hydrolytic degradation of dental composites. J Dent Res 1984; 63: 1248-1254. 